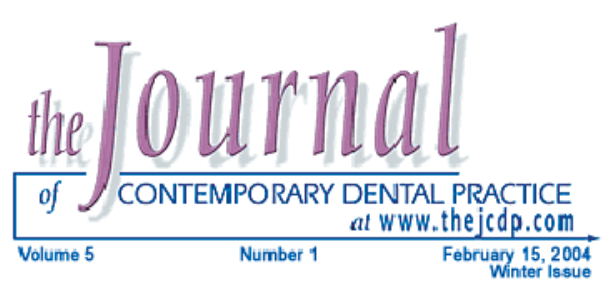

\title{
Influence of Passive Ultrasonic Activation on the Penetration Depth of Different Sealers
}

\section{Sibel Karadağ, DDS; A. Cemal Tınaz DDS, PhD; \\ Tansev Mıhçıoğlu, DDS, PhD}

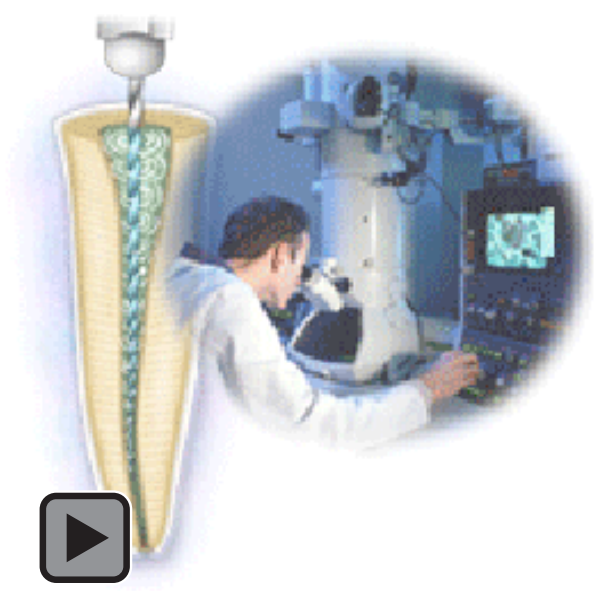

Abstract

Correct use of instruments and irrigating solutions are major factors during chemo-mechanical preparation of root canals. Ultrasonically activated files and solutions are used for debridement of canals. In this study 42 single rooted anterior human teeth were used. The roots were divided into two groups. One group received an application of $17 \%$ ethylenediamine tetra acetic acid (EDTA) of $1 \mathrm{ml}$ for $1 \mathrm{~min}$ using an ultrasonically energized file. The other group received an application of $17 \%$ EDTA of $1 \mathrm{ml}$ for $0.5 \mathrm{~min}$ using an ultrasonically energized file. The groups were divided again into two subgroups. The roots were filled with a resin based sealer, AH26 and a glass ionomer sealer - Endion with lateral condensation technique. The roots were separated into two halves. The specimens were viewed through a scanning electron microscope (SEM). Statistical differences between the groups and regions were analyzed with Variance and Duncan tests. Under the conditions of this study, it can be said that ultrasonically activated irrigation did not reduce the smear layer effectively at $1 \mathrm{~min}$ and 0.5 min time intervals. According to this result, no difference was observed between the penetration of sealers.

Keywords: Endion, EDTA, ultrasonics, depth of penetration

Citation: Karadag̈ LS, Mıhçıölu T, Tınaz AC. Influence of Passive Ultrasonic Activation on the Penetration Depth of Different Sealers. J Contemp Dent Pract 2004 February;(5)1:115-125.

(C) Seer Publishing 


\section{Introduction}

Root canal treatment can be summarized as a series of procedures for cleaning, shaping, and filling the root canal system. During treatment, probably the most important procedure is the chemo-mechanical preparation that is commonly based on the correct use of instruments and irrigating solutions.

In 1982, Cunningham and Martin ${ }^{1}$ introduced a commercial ultrasonic unit which can be used for endodontic purposes. When a file is ultrasonically activated and placed passively in a canal, a phenomenon called acoustic streaming is produced. ${ }^{2}$ Acoustic streaming is one of the purported mechanisms for superior debridement. It produces shear stresses that are capable of disrupting biological cells and removing debris. ${ }^{3}$

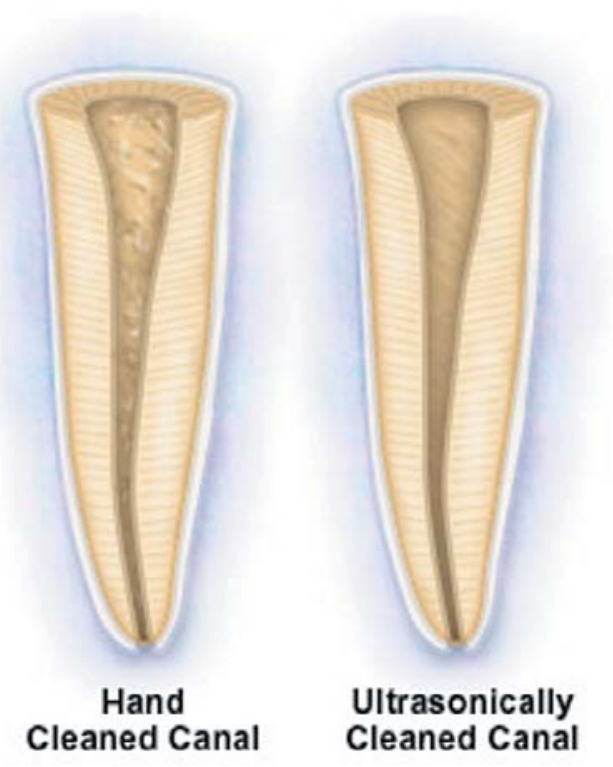

Ultrasonically prepared teeth are shown to have cleaner canals than the teeth prepared by hand instrumentation. ${ }^{4 \cdot 5}$ However some studies have failed to demonstrate the superiority of ultrasonics or sonics as a primary instrumentation technique. ${ }^{6,7}$ Perhaps a more effective technique for canal debridement would be to passively activate a file, ultrasonically, inside the canal as a final step in root canal preparation. Passive activation implies that no attempt is made to instrument, plane, or contact the canal walls with the file. This should allow for the maximum benefits from acoustic streaming. ${ }^{8}$
The purpose of this study was to compare the cleaning efficacy of passive ultrasonic activation using an ethylenediamine tetra acetic acid (EDTA) chelating agent and to discuss the dentin tubule penetration of two different sealers.

\section{Materials and Methods}

Forty-two single-rooted anterior human teeth were used. The specimens were stored in saline at all times except during canal preparation. To facilitate measurement and instrumentation, the crowns of all 42 teeth were cut and removed at the cemento-enamel junction level. The working length of all teeth was established by passing a \# $10 \mathrm{~K}$-file (Antaeos, VDW GmbH, München, Germany) to the apical foramen and then reducing the length by $0.5-1.0 \mathrm{~mm}$. The roots were then instrumented conventionally with \#10 to \#60 K files (Antaeos, VDW GmbH, München, Germany) by one operator. One milliliter of $2.65 \% \mathrm{NaOCl}$ solution was used as a canal irrigant prior to the insertion of each instrument. A laterally perforated needle with a closed end was used during irrigation to allow maximum penetration of the irrigation solution. Upon completion of the instrumentation, the roots were randomly divided into two equal groups of $A$ and $B$.

The roots in group $A$ received an application of 17\% EDTA of $1 \mathrm{ml} \mathrm{\# 15} \mathrm{Ni-Ti} \mathrm{file} \mathrm{energized} \mathrm{by}$ ultrasound was introduced $1 \mathrm{~mm}$ short from the anatomical apex for 1 min with small amplitude filing movements. Great care was paid to avoid touching the canal walls. The roots in group B

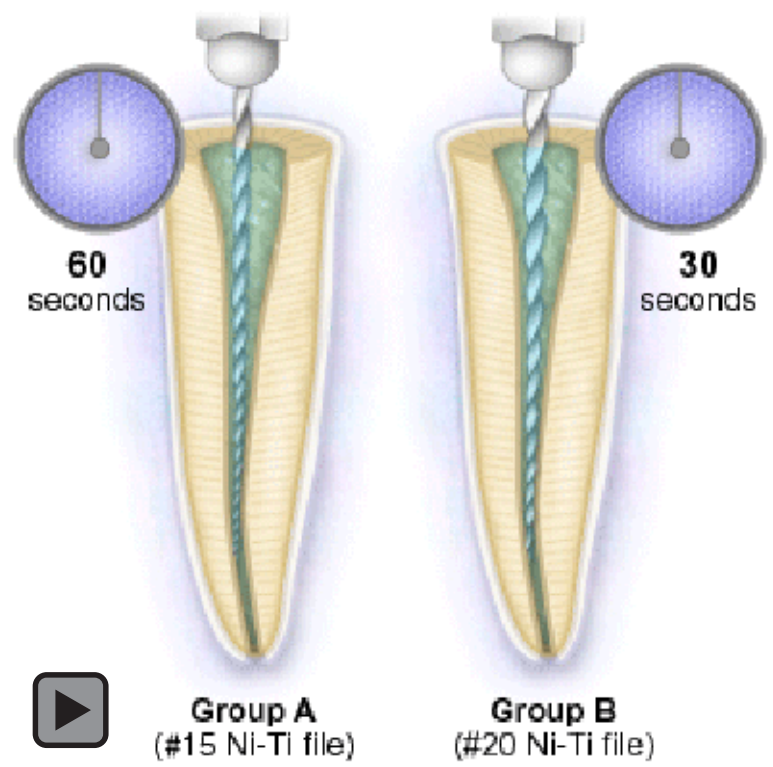


were filled again with 17\% EDTA \#20 0.02 taper $\mathrm{Ni}$-Ti file (HERO 642, Micro-Mega, Besançan, France) was introduced $1 \mathrm{~mm}$ short from the anatomical apex and energized by ultrasound for 30 seconds.

Treatment was then completed for both groups with a final $2.5 \mathrm{ml}$ rinse of $\mathrm{NaOCl}$ for $30 \mathrm{sec}$; this was standardized for all teeth. The canals were dried with paper points (DiaDent, Group Int. Inc. CA). According to the sealers used, the groups were again divided into two equal subgroups. The sealers used were a resin based sealer AH26 (De-Trey, Switzerland) and a glassionomer sealer Endion (Voco-Germany). They were prepared according to the manufacturers' instructions and the canals were filled with lateral condensation technique. Two roots were left empty as control groups; one from group $A$ and the other from group $B$. The excess gutta percha was removed from the coronal part of the canal with a heated instrument and the coronal access was sealed with Cavit (Espe, Seefeld Oberb, Germany). The roots were then stored at $37^{\circ} \mathrm{C}$ and $100 \%$ humidity for 10 days. To facilitate fracture, two parallel, longitudinal grooves which did not penetrate the root canal were made on two opposite external surfaces of each root. The roots were then fractured using end-cutting pliers. The root halves were mounted on aluminum stubs, coded, placed in a desiccator for 48 hours, and then coated with a thin $\left(200 \mathrm{~A}^{\circ}\right)$ palladium-gold film.

The specimens were viewed through a scanning electron microscope (SEM) (Jeol 6400, Noran Instruments) x2500 magnification. Low and high power electron photomicrographs were obtained of the coronal, middle, and apical thirds of each root. The focus of observation was the interface between the dentin and the sealer material. Data were expressed in £gm and statistical analyses were performed using a two-way analysis of variance with repeated measurements. Repeated measurements were performed on regions using the Duncan test.

\section{Results}

It was found the penetration depth of the AH26 sealer was $0-27.16 \mu \mathrm{m}$ and the sealer consisted of large particles densely packed in the dentinal tubules (Figure 1).
It was also observed the penetration depth of Endion sealer was 0-22.15 $\mu \mathrm{m}$ and the sealer consisted of irregularly shaped, high coherence crystals (Figure 2).

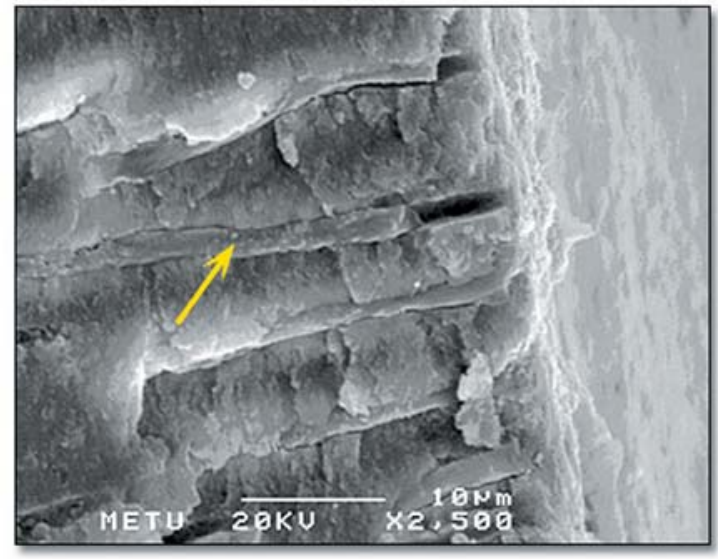

Figure 1. SEM showing the penetration of $\mathrm{AH} 26$ sealer in the middle part of the root.

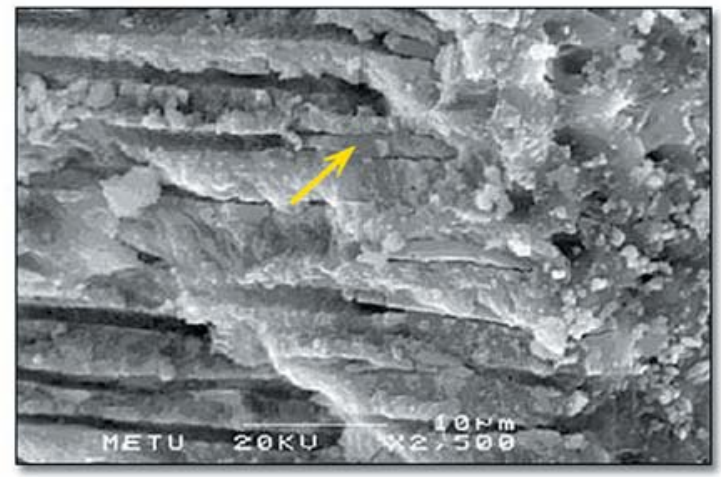

Figure 2. SEM showing the penetration of Endion sealer in the middle part of the root.

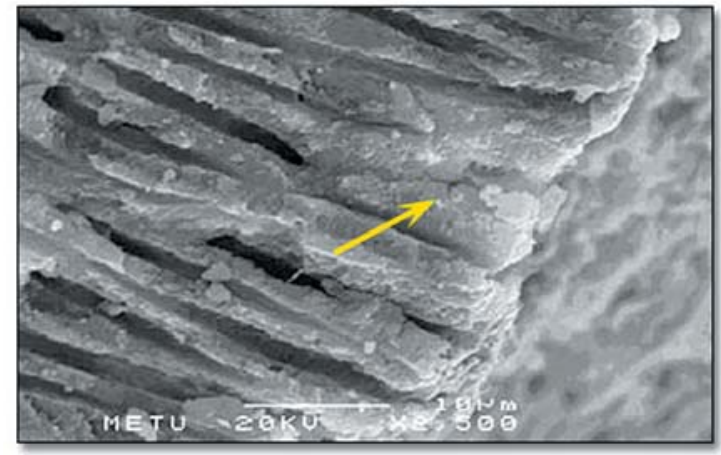

Figure 3. SEM showing the apical part of the root that was filled with Endion.

SEM microphotographs revealed the penetration of either sealer was insufficient in the apical parts of the roots (Figure 3). 
In the control group, orifices of the dentin tubules were open but the smear layer was left intact (Figure 4).

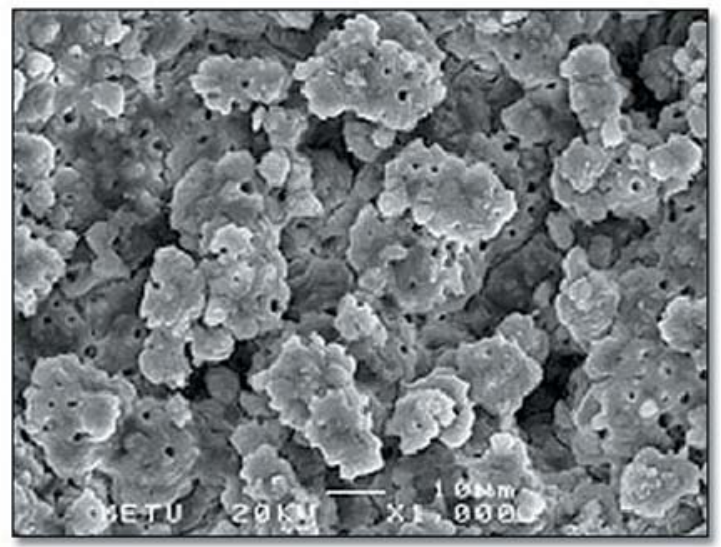

Figure 4. SEM showing the root surface of the control group.

The two factors we analyzed for the statistical tests were group and the region factor. The groups were as follows:

- Group A1: Roots treated with EDTA for 1 min then filled with $\mathrm{AH} 26$ sealer and lateral condensation technique.

- $\quad$ Group B1: Roots treated with EDTA for 30 sec then filled with $\mathrm{AH} 26$ sealer and lateral condensation technique.

- Group A2: Roots treated with EDTA for 1 min then filled with Endion sealer and lateral condensation technique.

- Group B2: Roots treated with EDTA for 30 sec then filled with Endion sealer and lateral condensation technique.

The regions of the root analyzed were coronal, middle, and apical, respectively. The group factor has four levels: A1, B1, A2, and B2; in the group factor, there were no statistically significant differences (Table 1).
The observations between the regions were analyzed using the Duncan test, and the results showed statistically significant differences at ( $P$ < 0.01) (Table 2). The coronal-apical part and middle-apical parts showed statistically significant differences.

\section{Discussion}

The aim of this study was to test the role of ultrasonic activated irrigation on the cleanliness of root canal walls and the penetration depth of different sealers. The oscillation of the tips of ultrasonic instruments is decreased by constraining it in the root canal. Because the amplitude of the oscillation is largest at the instruments tip, any attenuation affects the apical part most significantly. ${ }^{9}$ The current results confirm the apical part of canals was least influenced by the activated irrigation.

EDTA shows its activity by chelating $\mathrm{Ca}$ ions in dentine. Because its a chelating agent, EDTA is not dependent on a high hydrogen ion concentration to accomplish decalcification and is effective at neutral $\mathrm{PH} .{ }^{10}$ EDTA was used to improve canal debridement and to make the instrumentation process easier in the narrow canals, but nowadays it is also used after preparation for a final rinse to remove the smear layer.

For effective action, EDTA must be in direct contact with the surfaces. It is suggested EDTA should be applied for 3 min to remove the smear layer effectively. ${ }^{8}$ However, this application time is too long to hold these handpieces steady and passively in root canal procedures. At the beginning of this study, it was thought applying EDTA with ultrasonic energy after hand instrumentation at shorter time intervals, such as $1 \mathrm{~min}$ and 0.5 min, should remove the smear layer easily. To improve surface contact, EDTA solution was activated with ultrasonic energy. Although passive

Table 1.

A1: Roots treated with EDTA for 1 min then filled with AH26 sealer and lateral condensation technique.

B1: Roots treated with EDTA for $30 \mathrm{sec}$ then filled with AH26 sealer and lateral condensation technique.

A2: Roots treated with EDTA for 1 min then filled with Endion sealer and lateral condensation technique.

B2: Roots treated with EDTA for $30 \mathrm{sec}$ then filled with Endion sealer and lateral condensation technique.

\begin{tabular}{|c|c|c|c|c|}
\hline Groups & Mean $(\mu \mathrm{m})$ & Std. Error & Minimum & Maximum \\
\hline $\mathrm{A} 1$ & 11.694 & 2.747 & 5.573 & 17.816 \\
\hline B1 & 8.028 & 2.379 & 2.727 & 13.330 \\
\hline A2 & 7.604 & 2.747 & 1.383 & 13.626 \\
\hline B2 & 3.437 & 2.379 & -1.865 & 8.738 \\
\hline
\end{tabular}


Table 2. The results obtained by Duncan test.

\begin{tabular}{|l|l|l|}
\hline Regions & Mean difference & Std error \\
\hline Coronal-middle & -4.454 & 2.663 \\
\hline Coronal-apical & $6.110^{\star}$ & 2.124 \\
\hline Middle-coronal & 4.454 & 2.663 \\
Middle-apical & $10.564^{\star}$ & 2.019 \\
Apical-coronal & $-6.110^{*}$ & 2.124 \\
\hline Apical-middle & $-10.564^{*}$ & 2.019 \\
\hline
\end{tabular}

*The mean difference is significant at the .01 level

activation of ultrasonics after hand instrumentation produced cleaner canals, no technique was able to debride the canal system completely. Debris was observed at all levels of the canal system, but tended to be concentrated in the apical portion of the root.

In the current study, irrigation times of $1 \mathrm{~min}$ and 0.5 min each for EDTA and $\mathrm{NaOCl}$ were selected after canal preparation, as this seems clinically practical. The clinical relevance of this study indicated that activated irrigation did not significantly reduced smear layer when using ultrasonic energy. However further studies are needed for the removal of the smear layer by using ultrasonic energy with irrigation times $1 \mathrm{~min}$ and $0.5 \mathrm{~min}$.

The $\mathrm{AH} 26$ sealer penetrated into the dentinal tubules deeper than the Endion sealer. This may be attributed to the smaller size of its particle and its viscosity. Aktener et al. ${ }^{11}$ suggests the surface tension of the sealers determines the depth of their penetration into the dentinal tubules; the lower the tension, the higher the penetration level. It is possible that $\mathrm{AH} 26$ has a lower surface tension. Microstructure of the sealer paste in the dentinal tubules and the degree of their closure rather than the depth of penetration might be the most important factor for a tight obturation.

In this study, statistically no difference between the four groups was observed. Although the difference of the penetration between $\mathrm{AH} 26$ and Endion sealers was seen, this was not proven statistically. The penetration of sealers in the middle part of the tooth was found to be superior to the apical or coronal parts. The current results confirm the apical part of the canals was least influenced by the activated irrigation. It is because the chelating agent was unable to reach the apical part and remove the smear layer inspite of ultrasonic agitation. The penetration was better in the middle part. EDTA and ultrasonic agitation were especially effective in the middle part of the root canal, and the force required for the lateral condensation has proven the best in that region of the canal.

No statistical significances were found between the different times used for EDTA application, and it could not be shown that using ultrasonic irrigation has any superiority to others. The findings of this study are in accordance with the study which was made by Mayer et al. ${ }^{12}$

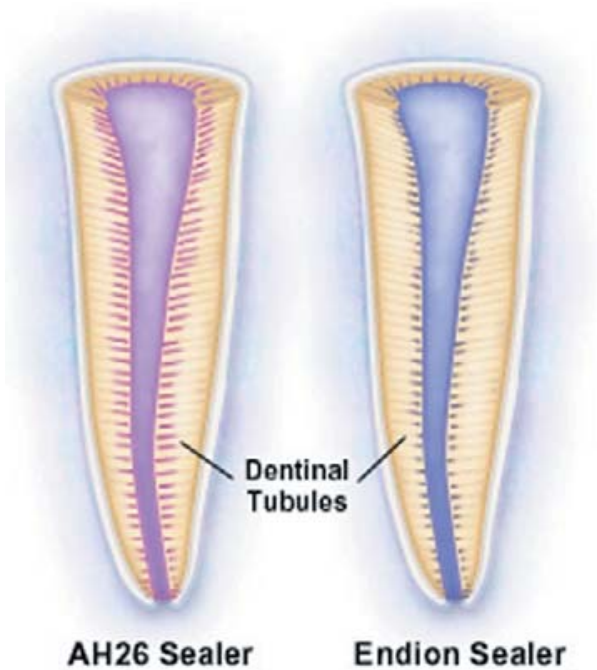

\section{Conclusion}

It seems the resin based sealer penetrated into dentinal tubules better then the glass ionomer sealer. Evaluated results have shown that statistically no significant difference was observed between the penetrations of sealers. Ultrasonically activated EDTA did not remove the smear layer effectively at $1 \mathrm{~min}$ and $0.5 \mathrm{~min}$ time intervals. 


\section{References}

1. Martin H, Cunningham WT, Norris JP, et. al. Ultrasonic versus hand filing of dentin: a quantitative study. Oral Surg Oral Med Oral Pathol. 1980;49(1):79-81.

2. Ahmad M, Pitt Ford TR, Crum LA. Ultrasonic debridement of root canals: an insight into the mechanisms involved. J Endod. 1987 Mar;13(3):93-101. No abstract available.

3. Williams AR. Disorganisation and disruption mammalian and ameboid cells by acoustic streaming. $J$ Acoust Soc Am 1972;52: 688-93.

4. Cunningham WT, Martin $\mathrm{H}$. A scanning electron microscope evaluation of root canal debridement with the endosonic ultrasonic synergistic system. Oral Surg Oral Med Oral Pathol. 1982 May;53(5): 527-31. No abstract available.

5. Stamos DE, Sadeghi EM, Haasch GC, et. al. An in vitro comparison study to quantitate the debridement ability of hand, sonic, and ultrasonic instrumentation. J Endod. 1987 Sep;13(9):434-40. No abstract available.

6. Reynolds WA, Madison S, Walton RE, et. al. An in vitro histological comparison of the step-back, sonic, and ultrasonic instrumentation techniques in small, curved root canals. J Endod. 1987 Jul;13(7):307-14. No abstract available.

7. Walker TL, del Rio CE. Histological evaluation of ultrasonic and sonic instrumentation of curved root canals. J Endod. 1989 Feb;15(2):49-59.

8. Jensen SA, Walker TL, Hutter JW, et. al. Comparison of the cleaning efficacy of passive sonic activation and passive ultrasonic activation after hand instrumentation in molar root canals. $J$ Endod. 1999 Nov;25(11):735-8.

9. Walmsley $A D$, Williams AR. Effects of constraint on the oscillatory pattern of endosonic files. $J$ Endod. 1989 May;15(5):189-94.

10. Guerisoli DM, Marchesan MA, Walmsley AD, et. al. Evaluation of smear layer removal by EDTAC and sodium hypochlorite with ultrasonic agitation. Int Endod J. 2002 May;35(5):418-21.

11. Aktener BO, Cengiz T, Piskin B. The penetration of smear material into dentinal tubules during instrumentation with surface-active reagents: a scanning electron microscopic study. J Endod. 1989 Dec;15(12):588-90.

12. Mayer BE, Peters OA, Barbakow F. Effects of rotary instruments and ultrasonic irrigation on debris and smear layer scores: a scanning electron microscopic study. Int Endod J. 2002 Jul;35(7):582-9. 

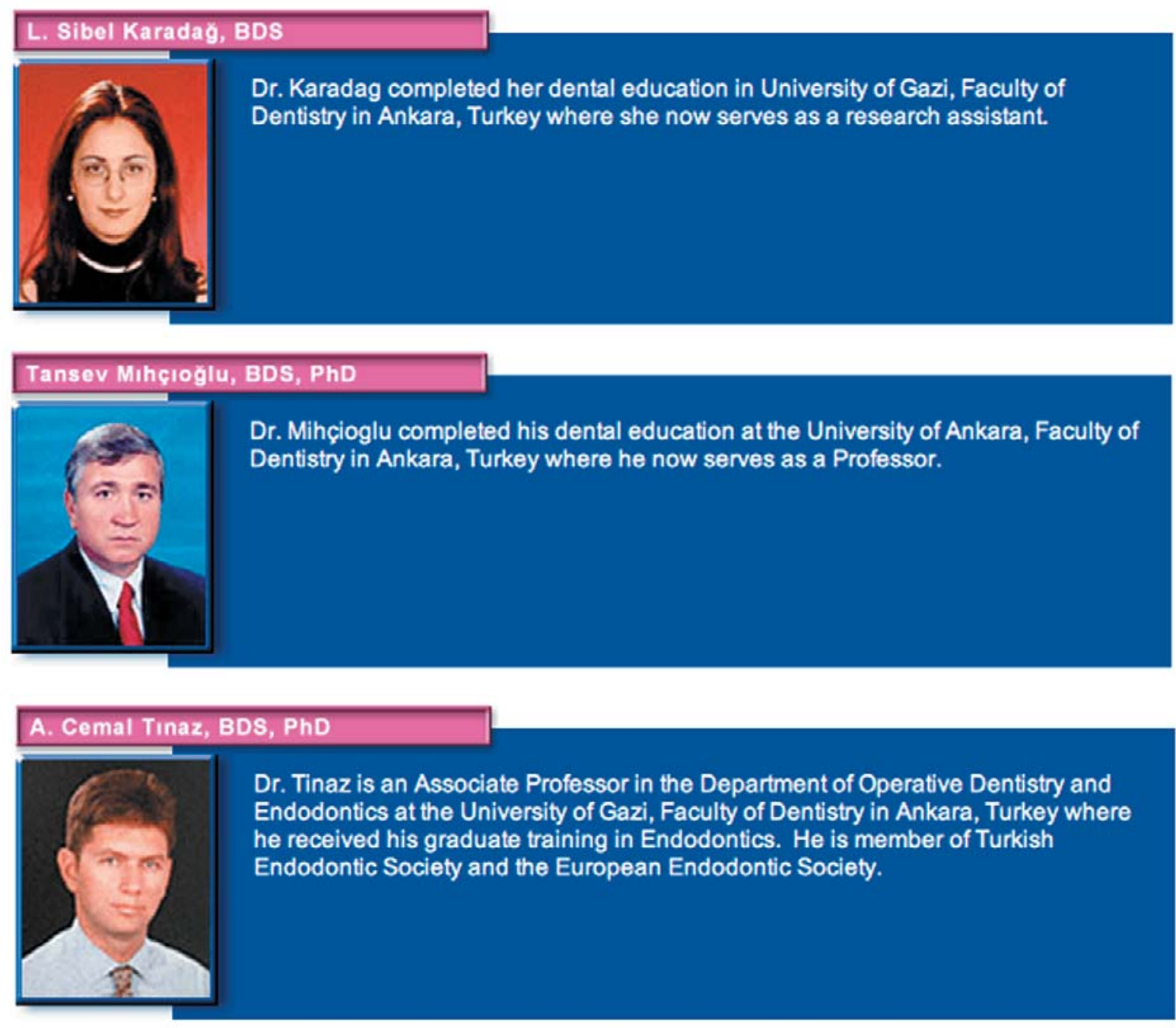

\section{Acknowledgements}

We express our sincere gratitude to Haluk Atala, MS, PhD, Prof. for his invaluable encouragement and Mr. Cengiz Tan for his assistance with SEM observations. 